\title{
Therapy Used Since Last Visit
}

National Cancer Institute

\section{Source}

National Cancer Institute. Therapy Used Since Last Visit. NCI Thesaurus. Code C157518.

An indication of the type of therapy used since the last visit. 